\title{
Cancer Research and Prevention Foundation
}

National Cancer Institute

\section{Source}

National Cancer Institute. Cancer Research and Prevention Foundation. NCI Thesaurus.

Code C39347.

The Cancer Research and Prevention Foundation is a national, non-profit health foundation whose mission is declared as the prevention and early detection of cancer through scientific research and education. The Foundation's expenses fall into two categories: research and education grants that are awarded to institutions, individuals and organizations, and are selected through a grant-review process approved by the National Institutes of Health. 